\title{
Indoor airborne particle sources and semi-volatile partitioning effect of outdoor fine PM in offices
}

\author{
G. Sangiorgi ${ }^{\mathrm{a}, *}$, L. Ferrero ${ }^{\mathrm{a}}$, B.S. Ferrini ${ }^{\mathrm{a}}$, C. Lo Porto ${ }^{\mathrm{a}}$, M.G. Perrone ${ }^{\mathrm{a}}$, R. Zangrando ${ }^{\mathrm{b}}$, A. Gambaro $^{\mathrm{b}, \mathrm{c}}$, \\ Z. Lazzati ${ }^{\mathrm{d}}$, E. Bolzacchini ${ }^{\mathrm{a}}$ \\ a Department of Environmental Sciences, University of Milano-Bicocca, piazza della Scienza 1, I-20126 Milano, Italy \\ ${ }^{\mathrm{b}}$ Institute for the Dynamics of Environmental Processes - CNR, Dorsoduro 2137, 30123 Venice, Italy \\ ${ }^{\mathrm{c}}$ Department of Environmental Sciences, Informatics and Statistics, University of Venice, Ca' Foscari, 30123 Venice, Italy \\ d Public Health Laboratory - Environmental Health and Water Chemistry, Local Public Health Unit USL 2, piazza Aldo Moro, 55012 Capannori, Lucca, Italy
}

\section{H I G H L I G H T S}

Indoor-to-outdoor relationship for PM1 and PM2.5 (I/O, $F_{\mathrm{INF}}$ and $\left.C_{\mathrm{ig}}\right)$.

- Chemical characterization of inorganic ions, PAHs and BpA in fine PM.

- More than $50 \%$ of urban (Milan) fine PM enters the indoor office environments.

$\checkmark$ Office indoor sources generate about $60 \%$ of indoor particulatebound BpA.

- Semi-volatile loss from outdoor PM when entering a warmer indoor environment.

\section{A R T I C L E I N F O}

\section{Article history:}

Received 30 May 2012

Received in revised form

7 October 2012

Accepted 8 October 2012

\section{Keywords:}

Indoor air quality

Polycyclic Aromatic Hydrocarbons

Inorganic ions

Bisphenol A

Indoor-to-outdoor ratio

Particulate matter

\section{G R A P H I C A L A B S T R A C T}

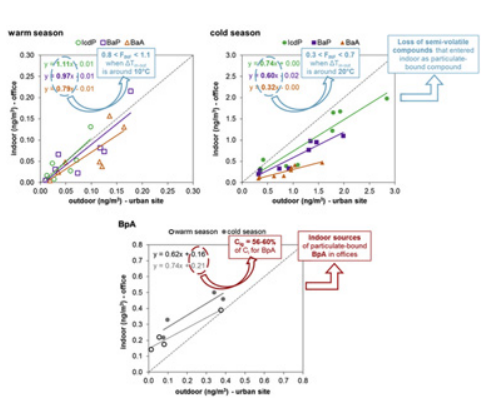

\begin{abstract}
A B S T R A C T
To date, few studies have focused on PM air quality in offices, despite the fact that a lot of people spend many working hours a day in such offices. The aim of the present study is to investigate PM1 and PM2.5 in offices in Milan (Northern Italy) and in the air outside those offices. The PM samples were analyzed to determine the entity of certain compounds with possible direct or indirect adverse effects on human health: PAHs, BpA, and water soluble inorganic ions.

A good correlation between outdoor and indoor PM mass concentrations emerged $\left(R^{2} \sim 0.87\right)$. The maximum $I / O$ concentration ratio was 0.92 , suggesting that the indoor PM level was always lower than the outdoor level. The average infiltration factor, $F_{\mathrm{INF}}$, was 0.55 , showing that about a half of the outdoor PM had come indoors. The indoor-generated particles, $C_{\mathrm{ig}}$, had values ranging from 0 to $4.4 \mu \mathrm{g} \mathrm{m}^{-3}$ ( $<25 \%$ of the indoor PM), showing that PM indoor sources had only made a limited contribution to total indoor PM.

The results of the indoor-to-outdoor comparisons for the aforementioned chemical compounds demonstrate that the offices were characterized by the absence of effective indoor sources of particulatebound PAHs and inorganic ions, whereas $C_{\mathrm{ig}}$ was around $58 \%$ of the indoor concentration for BpA. Our analysis of the $F_{\mathrm{INF}}$ data pointed to the presence of a volatilization effect from PM for semi-volatile compounds like ammonium nitrate and 4- or 5-ring PAHs, which affected the measurement of their $F_{\mathrm{INF}}$. We propose the introduction of a new and simple parameter, called volatilization correction, to take account of this effect.
\end{abstract}

(c) 2012 Elsevier Ltd. All rights reserved.

\footnotetext{
* Corresponding author. Tel.: +39 026448 2814; fax: +39 0264482839 .

E-mail address: giorgia.sangiorgi1@unimib.it (G. Sangiorgi).
} 


\section{Introduction}

Over the last twenty years or so, considerable efforts have been made to clarify the relationship between airborne particulate matter (PM) and human health, and a number of excellent accounts of this relationship are now available (e.g.: Englert, 2004; Lippmann et al., 2003; Valavanidis et al., 2008). Both the short-terms effects (premature mortality, hospital admissions, etc.) and the long-term effects (morbidity, lung cancer, cardiovascular and cardiopulmonary diseases, etc.) of PM have been described.

The toxicity associated with PM is related to both the size and the chemical composition of the particles in question. The smaller (fine and ultra-fine) PM particles have a greater ability to penetrate deeper into the lungs, and as a consequence the majority of studies conclude that they are basically more harmful. Moreover, the presence of specific compounds within the particles seems to increase their potential dangerousness.

Such compounds include several organic species, like Polycyclic Aromatic Hydrocarbons (PAHs) and Bisphenol A (BpA), as well as other inorganic species, such as elements. More specifically, certain PAHs have been classified as proven, probable or potential human carcinogens (International Agency for Research on Cancer). The action mechanisms of PAHs are still being studied, although results so far would seem to suggest that they can directly or indirectly damage DNA (Baird et al., 2005; Farmer et al., 2003). BpA is a suspected endocrine disruptor (Dodds, 1938). Despite the considerable number of studies of the distribution of BpA in different environmental compartments, very few focus on the atmosphere (Fu and Kawamura, 2010; Matsumoto et al., 2005; Wilson et al., 2001).

In addition to the aforementioned compounds, the acidity of the particles has also been associated with negative effects on human health, mainly in terms of lung functions. Many compounds concur to determine particle acidity, although it mainly results from the balance between sulfate and nitrate as acidic compounds, and ammonium as a neutralization species (Seinfeld and Pandis, 2006). Depending on ammonia availability, acidic sulfate and nitrate may be partially or totally neutralized in PM, thus determining particle acidity.
With regard to human health, air quality in indoor environments have been widely studied in recent years, with the focus primarily on schools and residential housing (e.g., Blondeau et al., 2005; Fromme, 2008; Martuzevicius, 2008; Polidori et al., 2009). On the contrary, considerably fewer studies have focused on PM levels in offices (Gemenetzis, 2006; Saraga et al., 2010), despite the fact that they are one of the most common workplaces in a great many countries, where lots of people spend a considerable part of their working day. As a consequence, indoor air quality in offices is of key importance, and is essential, from a health assessment point of view, when drawing up a detailed characterization of the most dangerous compounds present in the PM of offices.

A typical office is generally characterized by a very limited number of PM sources, which only occasionally contribute to indoor PM mass levels, whereas outdoor air quality can strongly affect the indoor environment. Office PM sources are represented by electronic equipment, such as: printers, photocopiers, multifunction office machines and computers (He et al., 2007; Koivisto et al., 2010; Ren et al., 2006; Wensing et al., 2008). Air conditioners (Fisk et al., 2000), together with human activity (Luoma and Batterman, 2001), can also generate PM.

The aim of the present study is to investigate PM pollution and its chemical characterization in offices in Milan and in the air outside those offices. Milan is the most densely populated, heavily polluted city in Northern Italy (Fig. 1). The service sector is the city's most important from the employment point of view, and many people spend a large part of their working day in such offices. Thus, the air quality in Milan's offices is very important for the health of a large number of workers. Moreover, the outdoor is a very strong particle source for indoor environments. The target of the study is fine PM (PM2.5 and PM1), which has been identified as the most dangerous fraction from a human health point of view. Moreover, the degree of infiltration of particles into buildings depends on particle size, and is lowest for the coarse fraction, PM2.5-10 (Hussein et al., 2005; McAuley et al., 2010). The PM samples were analyzed to determine some of the compounds with possible adverse effects on humans, i.e., PAHs, BpA, and water soluble inorganic ions.

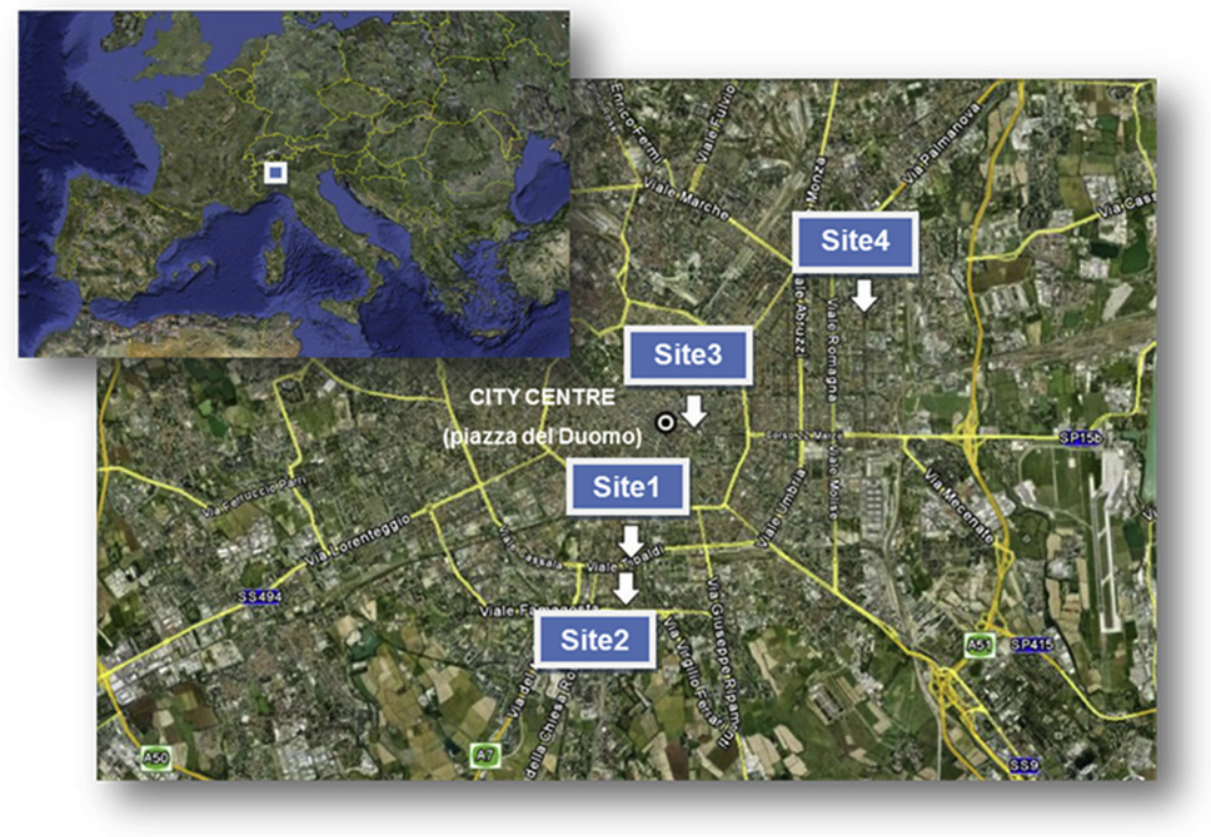

Fig. 1. Location of the four sampling sites distributed across the city of Milan, North Italy. 


\section{Methods}

\subsection{The sampling sites}

The study focused on the city of Milan in Northern Italy (Fig. 1). The high level of air pollution in the city has already been well documented (see Baltensperger et al., 2002; Vecchi et al., 2004), and it derives from both anthropogenic activities (mainly traffic and heating; Perrone et al., 2012) and weak atmospheric dispersal conditions (i.e., a short mixing layer), especially during the wintertime (Ferrero et al., 2011a, 2011b, 2010; Sangiorgi et al., 2011). The result is the presence of high emissions of air pollutants in a troposphere characterized by low dispersive movements.

Four sites were selected for the sampling of PM, all of them located within or immediately outside the inner city (Fig. 1). The sampling sites were chosen in order to have four distinct sampling positions with similar population densities, human activities and local pollutant sources. All of the four sites were located in areas characterized by considerable human activity and intense traffic. Four offices, one for each sampling site, were selected as our indoor environments. The buildings were representative of many of the inner Milan city's blocks. They were all built between the 1950s and the 1970s and none of them were renewed during the last 15 years. The perimeter walls were made of solid bricks and covered in plaster. The windows were made of wooden frames and single glass and were characterized by a low insulation. The general structure and preservation conditions of the buildings favored the penetration of the outdoor air. All the offices were at ground floor. They were characterized by the presence of a limited number of indoor PM sources. Smoking was forbidden, air supply systems were absent and the movement of people through the office was limited and occasional. The only possible indoor sources were the standard items of electronic equipment (computers, printers and photocopying machines) and the occasional movement of people. The characteristics of the sampling area (high pollution level) and indoor environment (no effective indoor sources) made it possible to highlight the impact of outdoor pollution on the indoor air.

\subsection{The sampling strategy}

Two sampling campaigns were conducted (Table 1): the first in summer and autumn (warm season; 22 Aug - 14 Oct 2007), the second in the winter (cold season; 15 Jan - 09 Mar 2008). Each site was sampled once during each campaign, for a period of 12 consecutive days. The samplings were not simultaneously performed at the four sites, in order to collect PM samples which were more representative of the variable seasonal conditions. No air conditioning systems were present in the offices. However, it should be noted that the environmental temperatures during the warm season were not so high, and that people in offices tended to keep the windows closed almost all the time to a similar extent during the two campaigns.

The sampling was performed at the same time both inside and outside the office building, using two identical low-volume samplers (38.3 $1 \mathrm{~min}^{-1}$, HYDRA dual channel, FAI Instruments, Rome, Italy). Both indoors and outdoors, 24-h samples of PM1 and PM2.5 were collected simultaneously on Teflon filters. In order to guarantee the quality of the PM measurements and chemical analyses, a number of field blank filters were used at each site during each campaign ( 28 field blank filters in all). The description of the sample handling and quality control of gravimetric data is presented in Supplementary Material (Section A).

\subsection{PM chemical characterization}

The collected filters were cut into multiple sections; one section of each daily filter was dedicated, individually or together with other sections from the same season, site and environment (indoor or outdoor), to determine the content of water-soluble inorganic ions, PAHs and BpA (BpA was only analyzed in PM2.5 samples). The composited samples were intended to raise the analytical signals.

As regards the sample filters, the field blank filters were cut into sections and analyzed, either individually or pooled in composited samples, to determine water-soluble inorganic ions, PAHs and BpA. The procedure was followed in order to determine any potential contamination of the samples from field and laboratory manipulation of the filters. The detection limit $(d l)$ was computed as the average plus three times the standard deviation (inorganic ions and PAHs) or three times the standard deviation (BpA) of the field blank concentration (Tab. SM1). Only those figures above $d l$ were admitted as valid. The following is a brief description of the analytical procedures (details are in Perrone et al., 2010, 2012). For sample processing and analysis to determine $\mathrm{BpA}$, see the Supplementary Material (Section B).

\subsubsection{Water-soluble inorganic ions}

The water-soluble inorganic ions were determined by extracting the composited samples in $3 \mathrm{ml}$ of ultra-pure water $\left(18.2 \mathrm{M} \Omega \mathrm{cm}^{-1}\right.$, Milli-Q water system, Millipore, Billerica, MA, USA) for $20 \mathrm{~min}$ in an ultrasonic bath $\left(\right.$ SONICA $^{\circledR}$, Soltec, Milan, Italy). The extract was filtered $(0.45 \mu \mathrm{m}$ pore size PTFE filter) and analyzed by two ion chromatographic systems (ICS-90 and ICS-2000, Dionex, Sunnyvale, CA, USA) coupled with an autosampler (AS, Dionex). An isocratic elution $\left(0.5 \mathrm{ml} \mathrm{min}^{-1}\right)$ and a chemical suppression mode were used. The method was used for the separation and quantification of the anions $\mathrm{F}^{-}, \mathrm{Cl}^{-}, \mathrm{NO}_{3}{ }^{-}, \mathrm{PO}_{4}{ }^{2-}, \mathrm{SO}_{4}{ }^{2-}$ and the cations $\mathrm{Na}^{+}, \mathrm{NH}_{4}{ }^{+}, \mathrm{K}^{+}, \mathrm{Mg}^{2+}, \mathrm{Ca}^{2+}$. Since the concentration of $\mathrm{F}^{-}, \mathrm{Cl}^{-}$and $\mathrm{PO}_{4}{ }^{3-}$ was always very low and close to $\mathrm{dl}$, they will not be taken into account

\subsubsection{Polycyclic Aromatic Hydrocarbons}

The PAHs were analyzed after extracting the composited samples using $2 \mathrm{ml}$ of acetonitrile (HPLC analyzed, Mallinckrodt Baker, Deventer, Holland) for $20 \mathrm{~min}$ in an ultrasonic bath. The extract was filtered ( $0.45 \mu \mathrm{m}$ pore size PTFE filter) and analyzed by means of high-pressure liquid chromatography with a fluorimetric detector (HPLC-FD, Shimadzu, Kyoto, Japan). The separation was performed on a C18 column (Vydac PAH column, Alltech,

Table 1

Dates of the indoor and outdoor sampling campaigns and average daily temperatures measured at the four sites (Milan, Italy).

\begin{tabular}{|c|c|c|c|c|c|c|c|c|}
\hline & \multicolumn{4}{|c|}{ Warm season } & \multicolumn{4}{|l|}{ Cold season } \\
\hline & \multicolumn{2}{|l|}{ Sampling } & \multicolumn{2}{|l|}{$T\left({ }^{\circ} \mathrm{C}\right)$} & \multicolumn{2}{|l|}{ Sampling } & \multicolumn{2}{|l|}{$T\left({ }^{\circ} \mathrm{C}\right)$} \\
\hline & Start & End & Outdoor & Indoor & Start & End & Outdoor & Indoor \\
\hline Site 1 & $22 / 08 / 2007$ & $02 / 09 / 2007$ & $19-28$ & $24-28$ & $26 / 02 / 2008$ & $09 / 03 / 2008$ & $6-16$ & $21-26$ \\
\hline Site 2 & $04 / 09 / 2007$ & $16 / 09 / 2007$ & $18-23$ & $23-26$ & $29 / 01 / 2008$ & $07 / 02 / 2008$ & $4-10$ & $20-24$ \\
\hline Site 3 & $18 / 09 / 2007$ & $30 / 09 / 2007$ & $11-21$ & $21-25$ & $12 / 02 / 2008$ & $24 / 02 / 2008$ & $3-12$ & $20-25$ \\
\hline Site 4 & $02 / 10 / 2007$ & $14 / 10 / 2007$ & $15-21$ & $20-25$ & $15 / 01 / 2008$ & $27 / 01 / 2008$ & $5-14$ & $22-25$ \\
\hline
\end{tabular}


Nicholasville, KY, USA) with a guard cartridge (Prosphere HPC18, Alltech). Acetonitrile and ultra-pure water were used in a gradient elution program $\left(1 \mathrm{ml} \mathrm{min}^{-1}\right)$. Ten PAHs were quantified: pyrene (PYR), benzo[a]anthracene (BaA), chrysene (CHR), benzo[b]fluoranthene $(\mathrm{BbF})$, benzo[k]fluoranthene $(\mathrm{BkF})$, benzo[e]pyrene $(\mathrm{BeP})$, benzo[a]pyrene (BaP), dibenz[a,h]anthracene (DBahA), indeno [1,2.3-cd]pyrene (IcdP), and benzo[ghi]perylene (BghiP). All the PAH concentrations were above $d l$, with the exception of DBahA, the level of which was often below it; as such, it will not be taken into consideration.

\subsubsection{Bisphenol $A$}

BpA was determined after extracting the composited samples in $0.5 \mathrm{ml}$ of methanol (LC-MS ChromaSolv ${ }^{\circledR}$ grade, $99.9 \%$ purity, Fluka, Sigma-Aldrich, Milan, Italy) for $10 \mathrm{~min}$ in an ultrasonic bath. The extract was filtered ( $0.45 \mu \mathrm{m}$ pore size PTFE filter) and analyzed by HPLC/(-)ESI-MS/MS (Agilent, Waldbronn, Germany) and a mobile phase constituted by ultra-pure water and methanol. Data were collected in negative ion mode by multiple reaction monitoring. Details of the method are set out in the Supplementary Material (Section B.1). All BpA concentrations in the samples were above $d l$.

\subsection{Indoor-outdoor relationship}

$I / O$ is the ratio between the indoor and outdoor concentration of $\mathrm{PM}$ or of a compound. It is a very simple, useful parameter, since it can be easily calculated and it enables to quickly establish whether the indoor environment is enriched with PM or compounds compared with the outdoor (e.g., Chen and Zhao, 2011; Hussein et al., 2005).

However, the indoor concentrations of PM and its chemical compounds are typically a mix of those from outside that come indoors, and those generated indoors, and the $I / O$ ratio does not enable to separate the two. Several studies have discussed this topic, showing that the indoor and outdoor concentrations can be linearly related in order to roughly separate the contributions made by the two sources. A simple linear equation is offered by many authors (e.g., Hänninen et al., 2004; Ho et al., 2004; Hoek et al., 2008):

$C_{\text {in }}=F_{\mathrm{INF}} \times C_{\text {out }}+C_{\text {ig }}$

where $C_{\text {in }}$ and $C_{\text {out }}$ are the PM or compound concentrations measured in the indoor and outdoor environments, respectively, $F_{\text {INF }}$ is the fraction of outdoor PM or compound that comes indoors and remain airborne, and $C_{\mathrm{ig}}$ is an estimate of the PM or compound concentration measured indoors and generated by indoor sources. $F_{\mathrm{INF}}$ is called the infiltration factor, $C_{\mathrm{ig}}$ is the indoor-generated particle concentration. Eq. (1) is derived from a more complex mass-balance model including parameters taking into account the indoor-outdoor air exchange rate, penetration efficiency, and particle deposition rate (Chen and Zhao, 2011; Hänninen et al., 2004). However, it should be pointed out here that there is no parameter that takes account of the potential loss of semi-volatile compounds from PM due to the shifting of its gas-particle partitioning equilibrium (e.g., resulting from a rise in temperature). The two approaches to the indoor-outdoor relationship will be presented in the following section. An ordinary least squares algorithm was used for the linear regression of Eq. (1).

\section{Results and discussion}

The concentration and chemical composition of PM are affected both by the sources of the area surrounding the sampling site, and by the meteorological conditions during the sampling campaign. In order to best represent the impact of the average meteorological conditions during a season (warm and cold), and of the PM sources within the urban Milan area, the sampling campaigns were conducted at four different sites throughout the city during different periods (Sections 2.1 and 2.2). As a consequence, we will not compare the results site by site, but we will focus on the relationship between outdoor and indoor PM features (Section 2.4.).

\subsection{PM mass concentration}

Fig. 2 and Table SM2 show the daily PM concentrations during the sampling campaigns; Table 2 summarizes the average values. The typical seasonal trend of ambient PM level for Milan emerges (Ferrero et al., 2011a, 2011b, 2010; Perrone et al., 2010): concentrations were lower during the summer and generally higher during the winter. It should also be noted that the sampling campaign from late September to October (Sites 3 and 4) revealed a "transition" period between the summer and winter levels of PM. Despite the variability of PM levels between sites and seasons, a good correlation between outdoor and indoor concentrations can be seen: $R^{2}$ was $0.86-0.88$ for PM1 and PM2.5 during both the seasons. Typically, PM1 represented about 70\% of PM2.5.

\subsubsection{Indoor-outdoor relationship of PM mass concentration}

The average $I / O$ was $0.64 \pm 0.13$, with a maximum of 0.92 , suggesting that the indoor level of PM concentration was always lower than the outdoor level. A slightly higher $I / O$ characterized PM1 (0.66 \pm 0.12 as average over the two campaigns) compared with PM2.5 (0.62 \pm 0.14$)$, as foreseen by previous studies (Hussein et al., 2005; McAuley et al., 2010).

Fig. 3 shows Eq. (1) for PM1 and PM2.5 during the warm and cold seasons. $F_{\mathrm{INF}}$ (i.e., the infiltration factor, the slope of the linear regression line) settled at about 0.55 and varied very little between PM sizes and campaigns. Thus, about a half of outdoor PM had come indoors, regardless of the season or the particle size (PM1 or PM2.5). It should be pointed out here that the windows of the offices were kept closed for most of the time during both sampling campaigns, given the likely autumnal temperatures measured outdoors during the warm season (Table 1), thus limiting the exchange of air between outdoors and indoors. This may explain the lack of a clear seasonal trend for $F_{\text {INF. }}$

During the warm season, the $C_{\text {ig }}$ (i.e., the indoor-generated particles, the intercept of the linear regression line) was positive, suggesting that few $\mu \mathrm{g} \mathrm{m}^{-3}$ of the indoor PM $\left(3.2 \pm 0.6 \mu \mathrm{g} \mathrm{m}^{-3}\right.$ for PM1; $4.4 \pm 0.9 \mu \mathrm{g} \mathrm{m}^{-3}$ for PM2.5) were generated by indoor sources, corresponding to about $25 \%$ of indoor PM concentrations. On the contrary, during the cold season, indoor-generated particles were absent $\left(C_{\mathrm{ig}}<0\right.$ : $-0.1 \pm 1.2 \mu \mathrm{g} \mathrm{m}^{-3}$ for PM1; $-1.8 \pm 1.9 \mu \mathrm{g} \mathrm{m}^{-3}$ for PM2.5). The $C_{\text {ig }}$ reveals the very limited contribution of indoor sources to fine PM mass concentration, which indeed fell to zero during the cold season.

\subsection{PM chemical composition}

The PM samples were analyzed to quantify the concentration of several compounds (Section 2.3): water-soluble inorganic ions, PAHs, and BpA. These chemical species include molecules that can have direct or indirect negative effects on human health (section 1). The results of the chemical characterization of fine PM will be presented and discussed below (Fig. 4, Tables SM3 and SM4). As regards PM mass concentration, we are not going to compare the data site by site, but to discuss the average value for each sampling site and season, with the focus on indoor-outdoor ratios (Section 2.4.). 

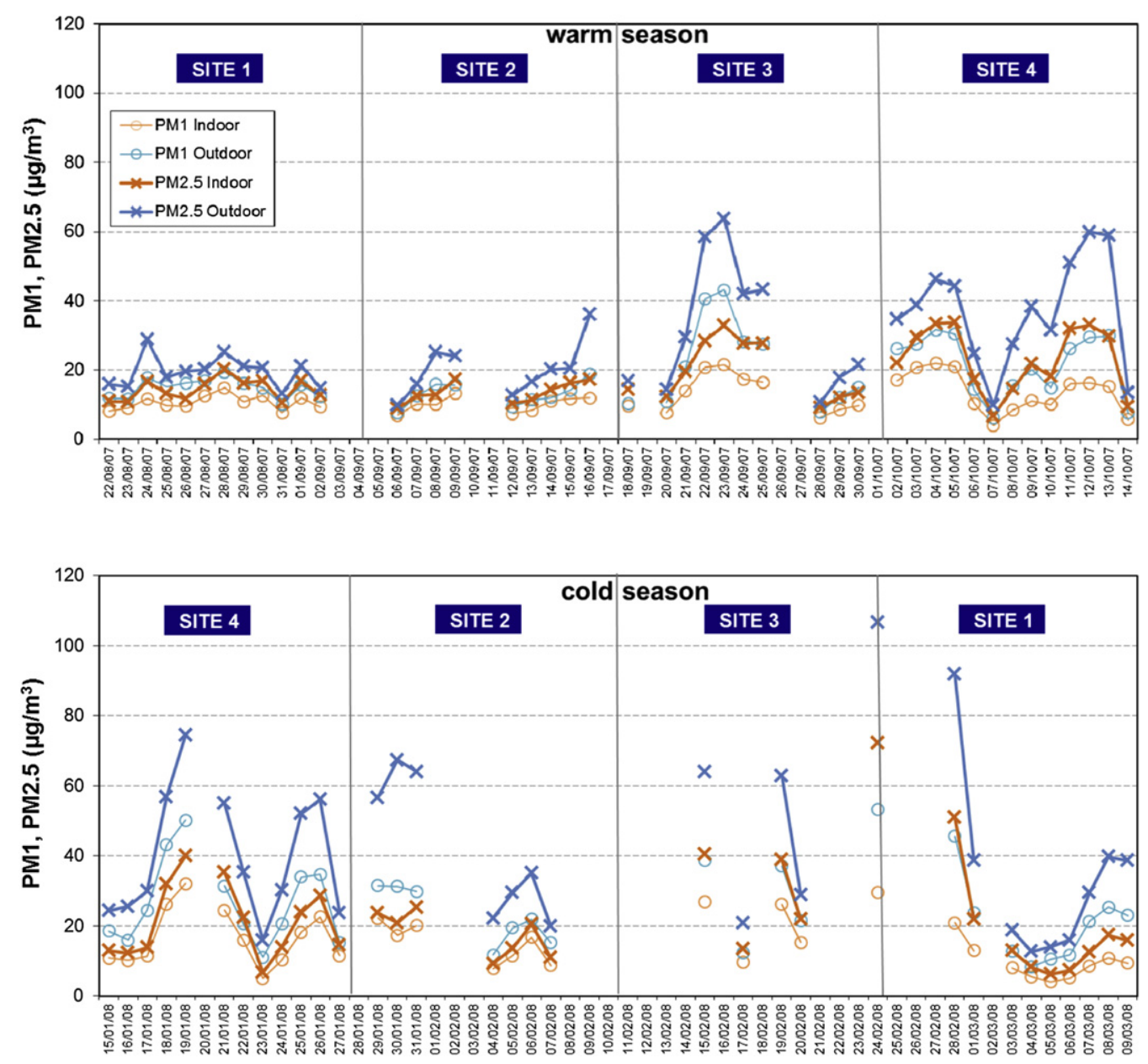

Fig. 2. Fine PM indoor (office) and outdoor (urban site) concentrations, measured during two sampling campaigns conducted at four sites in Milan (Italy).

A general seasonal trend is clear for all species, with site average concentrations higher during the cold season than during the warm season (for the PAHs, winter concentrations were of a greater magnitude).

The average concentration of the sum of the 7 inorganic ions $\left(\mathrm{NO}_{3}{ }^{-}, \mathrm{SO}_{4}{ }^{2-}, \mathrm{Na}^{+}, \mathrm{NH}_{4}{ }^{+}, \mathrm{K}^{+}, \mathrm{Mg}^{2+}, \mathrm{Ca}^{2+}\right)$ during the entire campaign was within the $4-27 \mu \mathrm{g} \mathrm{m}^{-3}$ range. A major fraction of PM was composed by inorganic ions, as their total mass accounted for $28 \%$ and $49 \%$ of indoor and outdoor PM respectively. $\mathrm{NO}_{3}{ }^{-}, \mathrm{SO}_{4}{ }^{2-}$ and $\mathrm{NH}_{4}^{+}$were the three main inorganic ions, each one accounting for about $30 \%$ of all ions. The average concentration of the sum of the 9 PAHs during the entire campaign was in the 0.5$13.0 \mathrm{ng} \mathrm{m} \mathrm{m}^{-3}$ range. The PAHs only made a very limited contribution to PM mass, which was about 6 times higher during the cold $(0.028 \pm 0.004 \%)$ than during the warm season $(0.005 \pm 0.001 \%)$. The average concentration of BpA during the entire campaign was $0.24 \pm 0.16 \mathrm{ng} \mathrm{m}^{-3}$ (min-max $0.01-$ $0.79 \mathrm{ng} \mathrm{m}^{-3}$ ) in PM2.5 (BpA was only analyzed in PM2.5 samples). The BpA concentration range in outdoor, from 0.01 to $0.73 \mathrm{ng} \mathrm{m}^{-3}$, is similar to that reported by Fu and Kawamura (2010) in PM2.5 samples collected along several outdoor urban sites of China $(0.02-$ $2.34 \mathrm{ng} \mathrm{m}^{-3}$ ). A higher range of concentration is showed for an urban-traffic site in Thessaloniki (Greece) by Salapasidou et al. (2011; 0.06-18.6 $\mathrm{ng} \mathrm{m}^{-3}$ ). The indoor concentration range, from 0.13 to $0.79 \mathrm{ng} \mathrm{m}^{-3}$, was lower than presented for similar indoor environments (houses and offices) by Inoue et al. (2006; up to $3.6 \mathrm{ng} \mathrm{m}^{-3}$ ). For a detailed description of the BpA field measurements, see the Supplementary Material (Section B.2).

\subsubsection{Indoor-outdoor relationships of PM chemical compounds}

The indoor-to-outdoor ratios of the compounds detected in PM samples will be described in the present section using $I / O$ and Eq.

Table 2

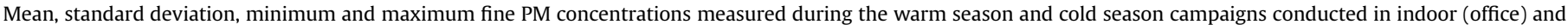
outdoor (urban site) environments (Milan, Italy).

\begin{tabular}{|c|c|c|c|c|c|c|c|c|}
\hline & \multicolumn{4}{|l|}{ Warm season } & \multicolumn{4}{|l|}{ Cold season } \\
\hline & \multicolumn{2}{|l|}{ Indoor } & \multicolumn{2}{|l|}{ Outdoor } & \multicolumn{2}{|l|}{ Indoor } & \multicolumn{2}{|l|}{ Outdoor } \\
\hline & PM1 $\left(\mu \mathrm{g} \mathrm{m}^{-3}\right)$ & PM2.5 $\left(\mu \mathrm{g} \mathrm{m}^{-3}\right)$ & PM1 $\left(\mu \mathrm{g} \mathrm{m}^{-3}\right)$ & PM2.5 $\left(\mu \mathrm{g} \mathrm{m}^{-3}\right)$ & PM1 $\left(\mu \mathrm{g} \mathrm{m}^{-3}\right)$ & PM2.5 $\left(\mu \mathrm{g} \mathrm{m}^{-3}\right)$ & PM1 $\left(\mu \mathrm{g} \mathrm{m}^{-3}\right)$ & PM2.5 $\left(\mu \mathrm{g} \mathrm{m}^{-3}\right)$ \\
\hline Mean & 12.1 & 18.1 & 18.1 & 27.6 & 15.0 & 21.9 & 25.0 & 41.1 \\
\hline Dev. St. & 4.5 & 7.8 & 8.7 & 14.8 & 7.8 & 14.3 & 12.0 & 23.3 \\
\hline Min & 4.1 & 6.9 & 6.4 & 9.9 & 4.1 & 6.2 & 8.4 & 12.8 \\
\hline Max & 22.1 & 33.8 & 43.2 & 63.8 & 32.1 & 72.3 & 53.1 & 106.5 \\
\hline
\end{tabular}



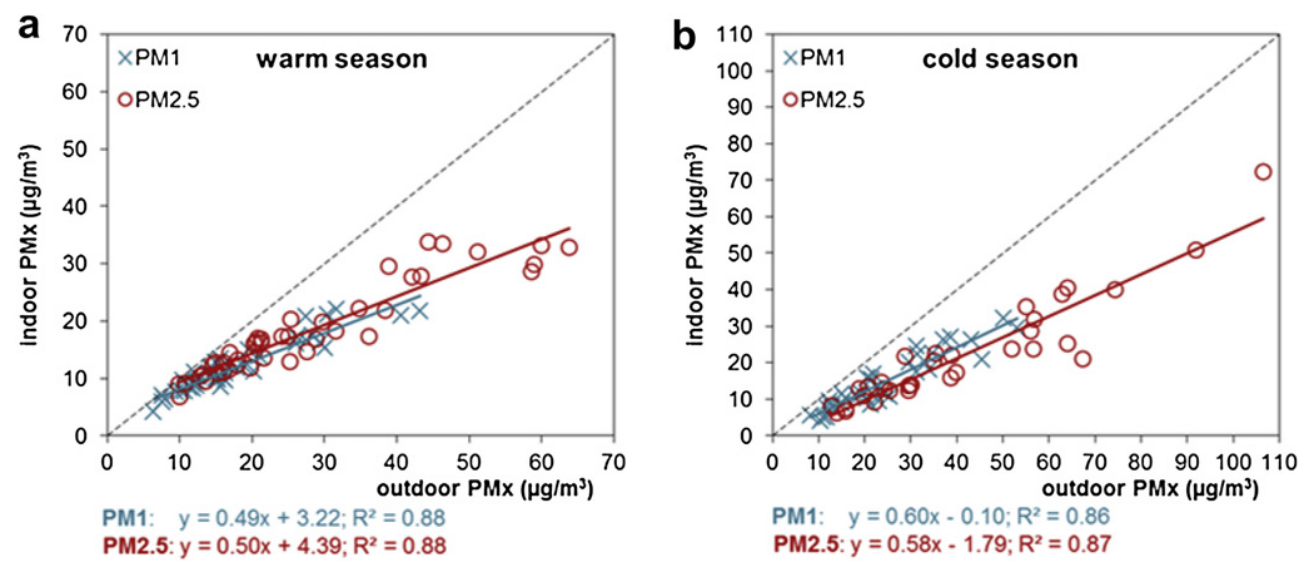

Fig. 3. Linear regression of outdoor (urban site) vs. indoor (office) fine PM concentrations at four sites of Milan (Italy) during a) warm and b) cold season campaigns.

(1) (Section 2.4). The slope and intercept of Eq. (1) were calculated for each analyte by means of linear regression (ordinary least squares). As a general rule, a good correspondence of the $I / O$ was found between PM1 and PM2.5 (Tables SM3 and SM4). As a consequence, we will refer to the $I / O$ ratio of each compound as the average of PM1 and PM2.5 taken together, sub-divided according to the two campaign seasons. Similarly, Eq. (1) was applied to the chemical composition data without separating the PM1 and PM2.5 samples, in order to extend the data set. The results are shown in Table SM5 and in Fig. 5.

3.2.1.1. Indoor-to-outdoor concentration ratios (I/O). Almost all of the $I / O$ were below or slightly above one, with the sole exception of $\mathrm{BpA}$, which revealed values of $2.42 \pm 1.51$ and $2.22 \pm 1.05$ during the warm season and the cold season, respectively (Table SM5). Of the other compounds, PAHs were characterized by a slightly narrower set of $I / O$ values than were the inorganic ions (the difference between the maximum and minimum $I / O$ was 1.0 and 0.3 during the warm season, and 0.7 and 0.5 during the cold season, for the inorganic ions and the PAHs respectively). Moreover, it appears that the $I / O$ values were always higher during the warm season than during the cold season, and the seasonal difference was more pronounced for PAHs than it was for inorganic ions or BpA.

3.2.1.2. Indoor-generated particles ( $C_{i g}$ ). By applying Eq. (1), a good correlation emerges between the indoor and outdoor concentrations of almost all the compounds: $R^{2}$ was above 0.6 , with very few exceptions ( $\mathrm{Ca}^{2+}$ and PYR). In general, the $C_{\mathrm{ig}}$ showed negative, or close to zero, values during the two sampling campaigns. Comparing it with the average indoor concentrations, it was always

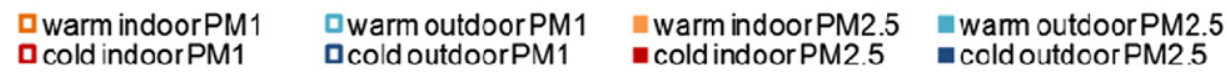
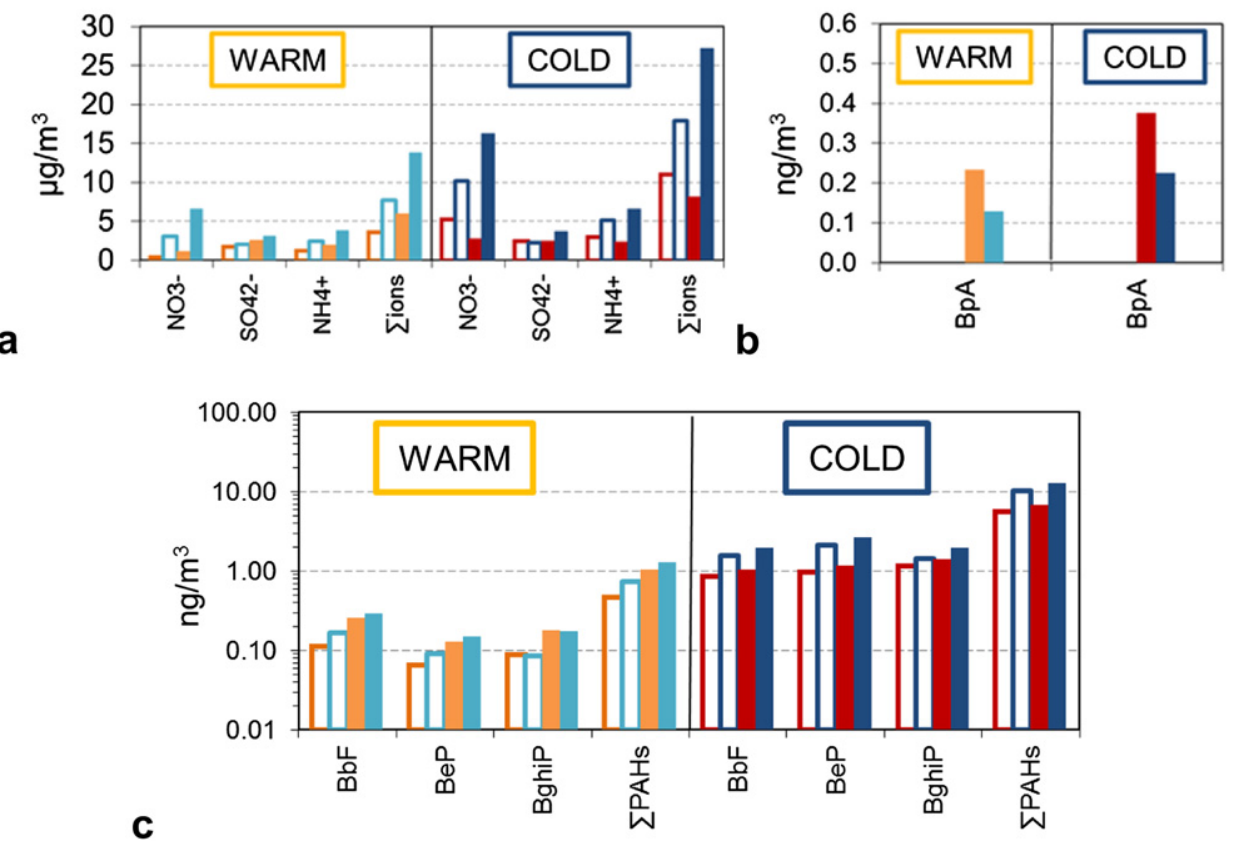

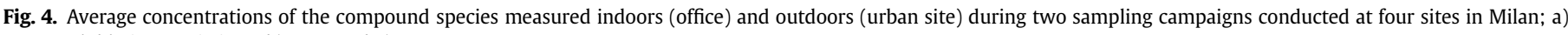
water-soluble inorganic ions, b) BpA, and c) PAHs. 
warm season

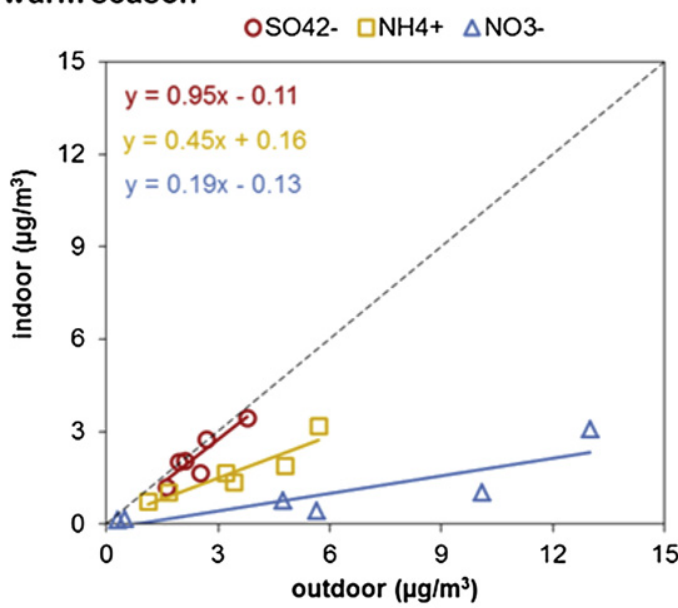

warm season

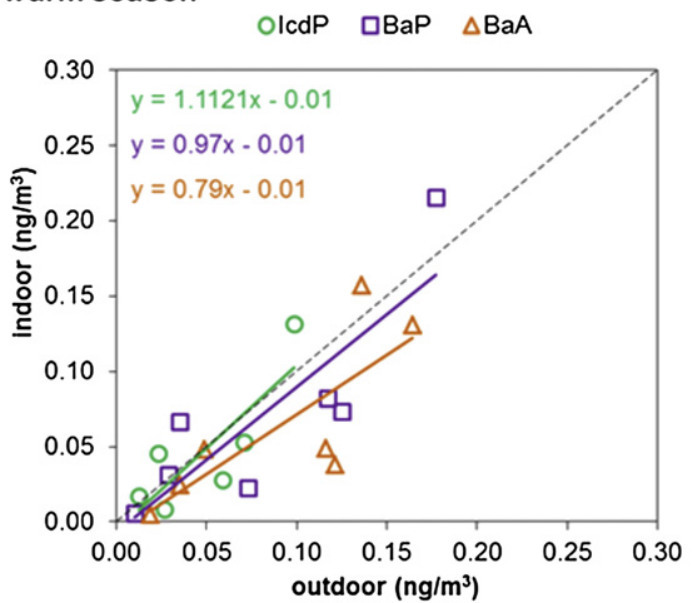

cold season

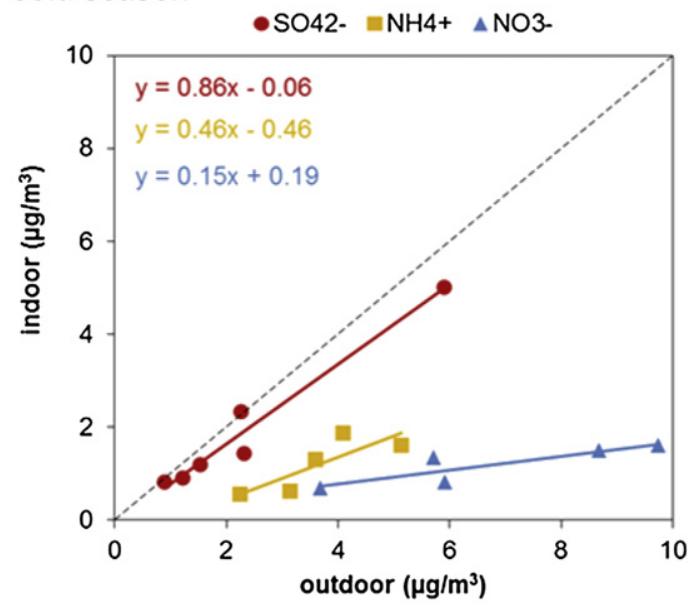

cold season

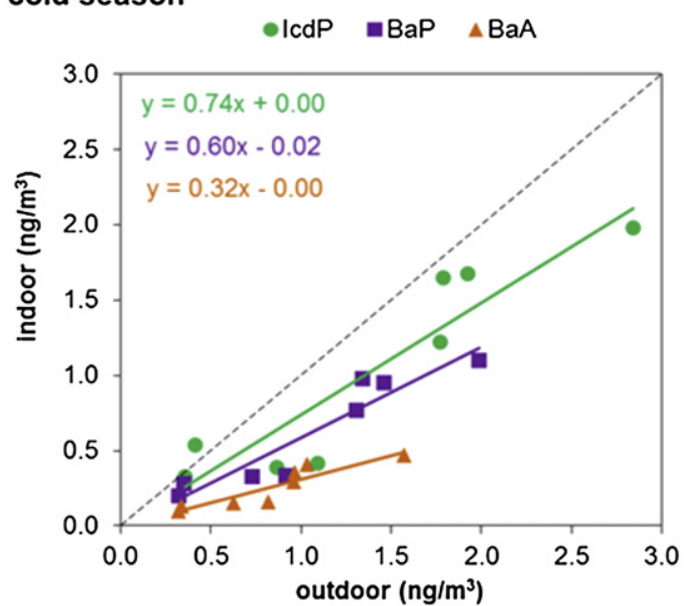

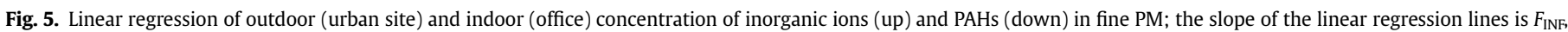
the intercept is $C_{\mathrm{ig}}$.

$\leq 20 \%$ (the less abundant inorganic ions $\mathrm{K}^{+}, \mathrm{Mg}^{2+}$ and $\mathrm{Ca}^{2+}$ displayed a $C_{\text {ig }}$ only slightly higher than $20 \%$ ). The main exception was $\mathrm{BpA}$, for which it was $60 \%$ and $56 \%$ during the warm and cold seasons, respectively. The results suggest that, as would be expected given the characteristics of the selected offices, there were no relevant indoor sources of the selected compounds. Only BpA had an actual indoor source that acted constantly during the two sampling periods. One possible indoor source of $\mathrm{BpA}$ is office equipment, such as computers and printers (Owens et al., 2007; Salapasidou et al., 2011).

3.2.1.3. Infiltration factor $\left(F_{I N F}\right)$. As with $I / O, F_{\mathrm{INF}}$ constantly displayed higher values during the warm season, when it generally stood above 0.7, than during the winter, when it stood under 0.7. However, it should be said that the highlighted seasonal trend was clear for the PAHs, for which $F_{\mathrm{INF}}$ fell from 0.8-1.2 during the warm season to $0.3-0.7$ during the cold season, whereas BpA and the inorganic ions in general tended to display very similar $F_{\mathrm{INF}}$ values during the two periods.

The analyzed species feature certain semi-volatile compounds, the transfer of which from the particulate to the gaseous phase

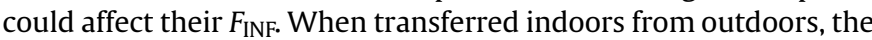
particle-bound compounds are subjected to a change in environmental conditions: as a rule, the temperature increases and the relative humidity decreases, particularly during winter. The gasparticulate partitioning is a process depending on both of the aforesaid parameters, especially temperature (Lohmann and Lammel, 2004; Ohura et al., 2004). When entering the warmer indoors, a semi-volatile molecule will tend to partition more in the gaseous phase, thus reducing its particulate concentration. This process is also facilitated by the adsorption of the gaseous compounds onto the indoor surfaces, which promotes a further movement of particulate semi-volatile molecules to the gaseous phase (Weschler and Nazaroff, 2008). Studies have shown that the new gas-particulate equilibrium for semi-volatile PAHs and ammonium nitrate entering buildings can be rapidly reached (Lunden et al., 2003; Naumova et al., 2003).

To demonstrate the semi-volatile loss for the volatilization effect on PM collected during the Milan campaigns, we divide the analyzed species into: a) non-volatile compounds (e.g., $\left(\mathrm{NH}_{4}\right)_{2} \mathrm{SO}_{4}$ and $\mathrm{Na}^{+}$), and b) semi-volatile compounds (e.g., 4-5 ring PAHs and $\mathrm{NH}_{4} \mathrm{NO}_{3}$ ).

As non-volatile molecules in $\mathrm{PM}, \mathrm{SO}_{4}{ }^{2-}$ (present as ammonium sulfate) and $\mathrm{Na}^{+}$are taken as a model. They were characterized by a high $F_{\text {INF }}$ during the two campaigns, which settled at about 0.9 . As expected for non-volatile species, the infiltration factor was not affected by the temperature differences between outdoors and indoors, or between warm and cold periods. 
Of the analyzed semi-volatile compounds, particulate ammonium nitrate exists in equilibrium with ammonia and nitric acid in the gas phase. The 4-ring PAHs partition themselves between the gas and particulate phases; the PAHs with 5 aromatic rings are more distributed in the particulate phase; PAHs with 6 or more rings are to be found almost exclusively in the particulate phase. Ammonium and nitrate displayed a fairly constant $F_{\mathrm{INF}}$ during the sampling campaigns, at around 0.17 and 0.45 for $\mathrm{NO}_{3}{ }^{-}$and $\mathrm{NH}_{4}{ }^{+}$, respectively. Of the PAHs, the 4-rings displayed the lowest values (PYR, BaA and CHR; average: 0.92 and 0.44 during the warm season and the cold season, respectively); the 5-rings displayed intermediate values (BbF, BeP, BaP, BkF, DBahA; 0.88 and 0.46); the 6-rings displayed the highest values (IcdP and BghiP; 1.17 and 0.72), with a decreasing $F_{\text {INF }}$ going from the warm to the cold season.

As regards the PAHs' behavior, the $F_{\text {INF }}$ trend reflected the compound's volatility: higher values were measured for the less volatile compounds. However, it is likely that the real $F_{\text {INF }}$ was very similar for all PAHs, although the more volatile compounds tended to be redistributed in the gaseous phase when coming indoors, leading to a reduction in their particulate concentration. The volatilization effect could also be the reason for the seasonal differences in the $F_{\mathrm{INF}}$ measured for the PAHs. In fact, the PM mass and non-volatile compound $F_{\mathrm{INF}}$ suggest the constant infiltration of particles during the two sampling campaigns. However, during the cold period the semi-volatile PAHs were subjected to a higher change in temperature when going from outdoors to indoors, and this probably favored a stronger transfer of them from the particulate to the gaseous phase. As a result, the $F_{\mathrm{INF}}$ decreased more, as the volatilization effect was stronger.

The seasonal trend described for the $F_{\mathrm{INF}}$ of PAH did not emerge in the case of ammonium nitrate. It is likely that ammonium nitrate and ammonium sulfate had the same $F_{\text {INF, but once indoors only }}$ ammonium nitrate - as a semi-volatile compound - tended to move toward the gaseous phase. Thereby, $\mathrm{NO}_{3}{ }^{-}$displayed a very low $F_{\text {INF }}$ because of the high volatility of ammonium nitrate, whereas $\mathrm{NH}_{4}{ }^{+}$displayed a $F_{\text {INF }}$ value somewhere between that of $\mathrm{NO}_{3}{ }^{-}$and $\mathrm{SO}_{4}{ }^{2-}$ because only the ammonium of ammonium nitrate - and not that of ammonium sulfate - was semi-volatile. The lack of a seasonal trend for the $F_{\mathrm{INF}}$ of ammonium nitrate is a consequence of its very high vapor pressure $\left(3 \times 10^{-3} \mathrm{mmHg}\right)$ : even a very small increase in temperature can affect the ammonium nitrate equilibrium in favor of the gaseous phase.

Several studies have reported indoor concentrations of ammonium nitrate or PAHs that are lower than would be expected due to solely penetration and deposition loss effects (e.g., John et al., 2007; Kliucininkas et al., 2011; Lunden et al., 2003; Naumova et al., 2003), thus supporting the volatilization effect of semi-volatile compounds in different situations. A detailed study of the gasparticulate distribution of PAHs both outdoor and indoor can be found in Naumova et al. (2003), that demonstrates a net decrease of PAHs concentration in the particulate phase. They attributed the described effect mainly to the temperature change (and, to a lesser extent, to the particulate content of elemental and organic carbon). The same was showed by Lunden et al. (2003) for ammonium nitrate, which measured indoor concentrations are significant lower than would be expected by penetration and deposition losses. They claimed that the dramatic reduction of particulate ammonium nitrate indoor should be attributed to the transfer in gaseous phase (as ammonia and nitric acid) as effect of the increase of their evaporation rate with the temperature increase.

\subsubsection{The volatilization effect of semi-volatile compounds}

Starting from the volatilization effect of semi-volatile compounds presented in the previous section, we propose the modification of Eq. (1) with the introduction of a new factor:
$C_{\text {in }}=F_{\text {exp }} \times C_{\text {out }}+C_{\text {ig }}$

where $F_{\exp }$ is the experimental infiltration factor, that is, the apparent infiltration factor of a compound calculated from the measured indoor and outdoor concentrations. It is equal to the real $F_{\text {INF }}$ for a non-volatile compound, but is affected by the volatilization effect for a semi-volatile compound. Thus, we propose the introduction of a corrective parameter, $v_{\mathrm{c}}$, called the volatilization correction, designed to take account of the loss of a semi-volatile compound that is partially redistributed to the gaseous phase when entering a warmer environment. It is calculated as follows:

$v_{\mathrm{c}}=F_{\mathrm{exp}} / F_{\mathrm{INF}-\mathrm{nv}}$

where the $F_{\mathrm{INF}-\mathrm{nv}}$ is the real infiltration factor, corresponding to the experimental infiltration factor of a non-volatile compound (e.g., $\left.\left(\mathrm{NH}_{4}\right)_{2} \mathrm{SO}_{4}\right)$. The $F_{\mathrm{INF}-\mathrm{nv}}$ depends on the penetration efficiency of $\mathrm{PM}$, the air exchange rate and the deposition rate of the particles. Eq. (2) can be re-written as follows:

$C_{\text {in }}=F_{\mathrm{INF}-\mathrm{nv}} \times v_{\mathrm{c}} \times C_{\mathrm{out}}+C_{\mathrm{ig}}$

The new correction parameter, $v_{\mathrm{c}}$, may range from 0 to 1 . It is 0 for a particle phase compound which, when entering a warmer indoor environment, will be redistributed completely in the gaseous phase. It is 1 for a non-volatile compound or a semivolatile compound that enters an indoor environment in which its gas-particle equilibrium does not change. An intermediate value of $v_{\mathrm{c}}$ would be associated to a semi-volatile compound (e.g., PAHs and $\mathrm{NH}_{4} \mathrm{NO}_{3}$ ) that experiences a gas-particle equilibrium change when entering a warmer environment. Clearly, $v_{\mathrm{c}}$ is mainly a function of compound volatility and temperature change. We are assuming here that the indoor sources emit compounds that very quickly achieve their gas-particle partitioning. In this way, $v_{\mathrm{c}}$ is not affected by $C_{\mathrm{ig}}$ (i.e., the gas-particle equilibrium of a semi-volatile compound is not affected by the indoor-generated particles).

The correction parameter $v_{\mathrm{c}}$ can be roughly estimated for $\mathrm{NH}_{4} \mathrm{NO}_{3}$ and PAHs (Table 3 ) in relation to the described sampling campaign conditions, taking $\left(\mathrm{NH}_{4}\right)_{2} \mathrm{SO}_{4}$ as a non-volatile compound and setting its $F_{\text {exp }}$ equal to $F_{\mathrm{INF}-\mathrm{nv}}$. The $v_{\mathrm{c}}$ kept the same value, during both seasons, for $\mathrm{NH}_{4} \mathrm{NO}_{3}$ (average: 0.19 ). On the contrary, all the PAHs displayed a $v_{c}$ close to one during the warm season, while during the cold period it was lower and varied according to the volatility of the compounds. The 4-ring PAHs displayed the lowest value ( 0.44 on average), followed by the 5-ring PAHs (0.59) and the 6-ring PAHs (0.84).

Table 3

Initial estimations of the volatilization correction parameter, $v_{c}$, for the semi-volatile ammonium nitrate and PAHs.

\begin{tabular}{lll}
\hline$V_{\mathrm{c}}$ & Season & \\
\cline { 2 - 3 } & Warm & Cold \\
\hline $\mathrm{NH}_{4} \mathrm{NO}_{3}$ & 0.20 & 0.17 \\
$\mathrm{PYR}$ & $/$ & 0.60 \\
$\mathrm{BaA}$ & 0.84 & 0.37 \\
$\mathrm{CHR}$ & 0.86 & 0.36 \\
$\mathrm{BbF}$ & $1.00^{\mathrm{a}}$ & 0.58 \\
$\mathrm{BkF}$ & 0.81 & 0.59 \\
$\mathrm{BeP}$ & $1.00^{\mathrm{a}}$ & 0.50 \\
$\mathrm{BaP}$ & $1.00^{\mathrm{a}}$ & 0.70 \\
IcdP & $1.00^{\mathrm{a}}$ & 0.86 \\
BghiP & $1.00^{\mathrm{a}}$ & 0.81 \\
\hline
\end{tabular}

${ }^{\mathrm{a}}$ Values $>1$ are set at 1. 


\section{Conclusions}

The research focused on the study of outdoor PM influence on indoor PM levels, and on the change in its chemical composition when coming indoors. The study was conducted in Milan, both outside and inside four typical office buildings, during the summer-autumn and the winter, and the target was fine PM (PM1 and PM2.5).

The results show the considerable influence of the outdoor environment on indoor PM, as confirmed by the strict correlation between indoor and outdoor PM concentrations $\left(R^{2}=0.86-0.88\right)$, and by the infiltration factor, which settled at about 0.55 regardless of PM size or the sampling period. However, the indoor concentrations were always lower than those measured outdoors (the maximum $I / O$ was 0.92 ), while any effective indoor source was highlighted $\left(C_{\mathrm{ig}} \leq 4 \mu \mathrm{g} \mathrm{m}^{-3}\right)$.

No significant indoor sources were found for the analyzed chemical compounds ( $C_{\mathrm{ig}} \leq 20 \%$ of the indoor concentrations of water-soluble inorganic ions and PAHs), with the exception of $\mathrm{BpA}$, the $I / O(\sim 2.3)$ and $C_{\mathrm{ig}}(\sim 58 \%)$ of which demonstrated the clear presence of indoor sources (e.g., printers and photocopiers). This is an important finding, as it proves the presence of indoor sources which did not contribute toward a high PM mass emission, but which significantly affected human health through the apportionment of particles enriched by dangerous compounds such as BpA.

A second important finding from the present study is the demonstration of the loss of semi-volatile compounds through volatilization from the particulate phase when outdoor PM comes indoors, mainly because of the increase in temperature. Clearly, this effect is greater for the more volatile compounds, such as ammonium nitrate, but lower in the case of less volatile compounds, such as 4- and 5-ring PAHs. This is an important process that affects the composition of indoor PM, and it should be taken into consideration when analyzing the infiltration factor $F_{\text {INF. Thus, we have }}$ proposed the introduction of a new parameter - the volatilization correction $v_{\mathrm{c}}-$ in order to include this process in the indoor-tooutdoor linear regression.

\section{Acknowledgments}

The authors would like to thank Dr. Elena D'Adda and Dr. Luigi Mensi for their support with the chemical analyses, and Dr. Stefania Petraccone for her help with the laboratory work. This research project was funded by the Municipality of Milan.

\section{Appendix A. Supplementary data}

Supplementary data related to this article can be found at http:// dx.doi.org/10.1016/j.atmosenv.2012.10.050.

\section{References}

Baird, W.M., Hooven, L.A., Mahadevan, B., 2005. Carcinogenic polycyclic aromatic hydrocarbon-DNA adducts and mechanism of action. Environmental and Molecular Mutagenesis 45, 106-114.

Baltensperger, U., Streit, N., Weingartner, E., Nyeki, S., Prévôt, A.S.H., Van Dingenen, R., Virkkula, A., Putaud, J.-P., Even, A., ten Brink, H., Blatter, A., Neftel, A., Gäggeler, H.W., 2002. Urban and rural aerosol characterization of summer smog events during the PIPAPO field campaign in Milan, Italy. Journal of Geophysical Research 107, 8193.

Blondeau, P., Iordache, V., Poupard, O., Genin, D., Allard, F., 2005. Relationship between outdoor and indoor air quality in eight French schools. Indoor Air 15 $2-12$.

Chen, C., Zhao, B., 2011. Review of relationship between indoor and outdoor particles: $I / O$ ratio, infiltration factor and penetration factor. Atmospheric Environment 45, 275-288.

Dodds, E.C., 1938. Molecular structure in relation to estrogenic activity. Compounds without a phenanthrene nucleus. Proceedings - royal society. Biological Sciences $125,222$.
Englert, N., 2004. Fine particles and human health-a review of epidemiological studies. Toxicology Letters 149, 235-242.

Farmer, P.B., Singh, R., Kaur, B., Sram, R.J., Binkova, B., Kalina, I., Popov, T.A., Garte, S., Taioli, E., Gabelova, A., Cebulska-Wasilewska, A., 2003. Molecular epidemiology studies of carcinogenic environmental pollutants: effects of polycyclic aromatic hydrocarbons (PAHs) in environmental pollution on exogenous and oxidative DNA damage. Mutation Research/Reviews in Mutation Research 544, 397-402.

Ferrero, L., Perrone, M.G., Petraccone, S., Sangiorgi, G., Ferrini, B.S., Lo Porto, C., Lazzati, Z., Cocchi, D., Bruno, F., Greco, F., Riccio, A., Bolzacchini, E., 2010. Vertically-resolved particle size distribution within and above the mixing layer over the Milan metropolitan area. Atmospheric Chemistry and Physics 10, 3915-3932.

Ferrero, L., Mocnik, G., Ferrini, B.S., Perrone, M.G., Sangiorgi, G., Bolzacchini, E., 2011a. Vertical profiles of aerosol absorption coefficient from microAethalometer data and Mie calculation over Milan. Science of the Total Environment 409, 2824-2837.

Ferrero, L., Riccio, A., Perrone, M.G., Sangiorgi, G., Ferrini, B.S., Bolzacchini, E., 2011b. Mixing height determination by tethered balloon-based particle soundings and modeling simulations. Atmospheric Research 102, 145-156.

Fisk, W.J., Faulkner, D., Sullivan, D., Mendell, M.J., 2000. Particle concentrations and sizes with normal and high efficiency air filtration in a sealed air-conditioned office building. Aerosol Science and Technology 32, 527-544.

Fromme, H., 2008. Chemical and morphological properties of particulate matter (PM10, PM2.5) in school classrooms and outdoor air. Atmospheric Environment 42, 6597-6605.

Fu, P., Kawamura, K., 2010. Ubiquity of bisphenol A in the atmosphere. Environmental Pollution 158, 3138-3143.

Gemenetzis, P., 2006. Mass concentration and elemental composition of indoor PM2.5 and PM10 in University rooms in Thessaloniki, northern Greece. Atmospheric Environment 40, 3195-3206.

Hänninen, O.O., Lebret, E., Ilacqua, V., Katsouyanni, K., Künzli, N., Srám, R.J., Jantunen, M., 2004. Infiltration of ambient PM2.5 and levels of indoor generated non-ETS PM2.5 in residences of four European cities. Atmospheric Environment 38, 6411-6423.

He, C., Morawska, L., Taplin, L., 2007. Particle emission characteristics of office printers. Environmental Science and Technology 41, 6039-6045.

Ho, K.F., Cao, J.J., Harrison, R.M., Lee, S.C., Bau, K.K., 2004. Indoor/outdoor relationships of organic carbon (OC) and elemental carbon (EC) in PM2.5 in roadside environment of Hong Kong. Atmospheric Environment 38, 6327-6335.

Hoek, G., Kos, G., Harrison, R., de Hartog, J., Meliefste, K., tenBrink, H., Katsouyanni, K., Karakatsani, A., Lianou, M., Kotronarou, A., Kavouras, I., Pekkanen, J., Vallius, M., Kulmala, M., Puustinen, A., Thomas, S., Meddings, C., Ayres, J., van Wijnen, J., Hameri, K., 2008. Indoor-outdoor relationships of particle number and mass in four European cities. Atmospheric Environment 42, 156-169.

Hussein, T., Hämeri, K., Heikkinen, M.S.A., Kulmala, M., 2005. Indoor and outdoor particle size characterization at a family house in Espoo-Finland. Atmospheric Environment 39, 3697-3709.

Inoue, K., Yoshida, S., Nakayama, S., Ito, R., Okanouchi, N., Nakazawa, H., 2006. Development of stable isotope dilution quantification liquid chromatography-mass spectrometry method for estimation of exposure levels of bisphenol A, 4-tertoctylphenol, 4-nonylphenol, tetrabromobisphenol A, and pentachlorophenol in indoor air. Archives of Environmental Contamination and Toxicology 51, 503-508.

John, K., Karnae, S., Crist, K., Kim, M., Kulkarni, A., 2007. Analysis of trace elements and ions in ambient fine particulate matter at three elementary schools in Ohio. Journal of the Air and Waste Management Association 57, 394-406.

Kliucininkas, L., Martuzevicius, D., Krugly, E., Prasauskas, T., Kauneliene, V., Molnar, P., Strandberg, B., 2011. Indoor and outdoor concentrations of fine particles, particle-bound PAHs and volatile organic compounds in Kaunas, Lithuania. Journal of Environmental Monitoring 13, 182-191.

Koivisto, A.J., Hussein, T., Niemelä, R., Tuomi, T., Hämeri, K., 2010. Impact of particle emissions of new laser printers on modeled office room. Atmospheric Environment 44, 2140-2146.

Lippmann, M., Frampton, M., Schwartz, J., Dockery, D., Schlesinger, R., Koutrakis, P., Froines, J., Nel, A., Finkelstein, J., Godleski, J., Kaufman, J., Koenig, J., Larson, T., Luchtel, D., Liu, L.J., Oberdorster, G., Peters, A., Sarnat, J., Sioutas, C., Suh, H. Sullivan, J., Utell, M., Wichmann, E., Zelikoff, J., 2003. The U.S. Environmental Protection Agency particulate matter health effects research centers program: a midcourse report of status, progress, and plans. Environmental Health Perspectives 111, 1074-1092.

Lohmann, R., Lammel, G., 2004. Adsorptive and absorptive contributions to the gasparticle partitioning of polycyclic aromatic hydrocarbons: state of knowledge and recommended parametrization for modeling. Environmental Science and Technology 38, 3793-3803.

Lunden, M.M., Revzan, K.L., Fischer, M.L., Thatcher, T.L., Littlejohn, D., Hering, S.V., Brown, N.J., 2003. The transformation of outdoor ammonium nitrate aerosols in the indoor environment. Atmospheric Environment 37, 5633-5644.

Luoma, M., Batterman, S.A., 2001. Characterization of particulate emissions from occupant activities in offices. Indoor Air 11, 35-48.

Martuzevicius, D., 2008. Traffic-related PM2.5 aerosol in residential houses located near major highways: indoor versus outdoor concentrations. Atmospheric Environment 42, 6575-6585.

Matsumoto, H., Adachi, S., Suzuki, Y., 2005. Bisphenol A in ambient air particulates responsible for the proliferation of MCF-7 human breast cancer cells and its concentration changes over 6 months. Archives of Environmental Contamination and Toxicology 48, 459-466. 
McAuley, T.R., Fisher, R., Zhou, X., Jaques, P.A., Ferro, A.R., 2010. Relationships of outdoor and indoor ultrafine particles at residences downwind of a major international border crossing in Buffalo, NY. Indoor Air 20, 298-308.

Naumova, Y.Y., Offenberg, J.H., Eisenreich, S.J., Meng, Q., Polidori, A., Turpin, B.J., Weisel, C.P., Morandi, M.T., Colome, S.D., Stock, T.H., Winer, A.M., Alimokhtari, S., Kwon, J., Maberti, S., Shendell, D., Jones, J., Farrar, C., 2003. Gas/particle distribution of polycyclic aromatic hydrocarbons in coupled outdoor/indoor atmospheres. Atmospheric Environment 37, 703-719.

Ohura, T., Amagai, T., Fusaya, M., Matsushita, H., 2004. Polycyclic aromatic hydrocarbons in indoor and outdoor environments and factors affecting their concentrations. Environmental Science \& Technology 38, 77-83.

Owens, C.V., Lambright, C., Bobseine, K., Ryan, B., Earl Gray, L., Gullett, B.K. Wilson, V.S., 2007. Identification of estrogenic compounds emitted from the combustion of computer printed circuit boards in electronic waste. Environmental Science \& Technology 41, 8506-8511.

Perrone, M.G., Gualtieri, M., Ferrero, L., Porto, C.L., Udisti, R., Bolzacchini, E. Camatini, M., 2010. Seasonal variations in chemical composition and in vitro biological effects of fine PM from Milan. Chemosphere 78, 1368-1377.

Perrone, M.G., Larsen, B.R., Ferrero, L., Sangiorgi, G., De Gennaro, G., Udisti, R., Zangrando, R. Gambaro, A., Bolzacchini, E., 2012. Sources of high PM2.5 concentrations in Milan, Northern Italy: molecular marker data and CMB modelling. Science of the Total Environment 414, 343-355.

Polidori, A, Cheung, K.L., Arhami, M., Delfino, RJ. Schauer, JJ. Sioutas, C, 2009. Relationships between size-fractionated indoor and outdoor trace elements at four retirement communities in southern California. Atmospheric Chemistry and Physics 9, 4521-4536.

Ren, Y., Cheng, T., Chen, J., 2006. Polycyclic aromatic hydrocarbons in dust from computers: one possible indoor source of human exposure. Atmospheric Environment 40, 6956-6965.
Salapasidou, M., Samara, C., Voutsa, D., 2011. Endocrine disrupting compounds in the atmosphere of the urban area of Thessaloniki, Greece. Atmospheric Environment $45,3720-3729$.

Sangiorgi, G., Ferrero, L., Perrone, M.G., Bolzacchini, E., Duane, M., Larsen, B.R., 2011 Vertical distribution of hydrocarbons in the low troposphere below and above the mixing height: tethered balloon measurements in Milan, Italy. Environmental Pollution 159, 3545-3552.

Saraga, D., Maggos, T., Sfetsos, A., Tolis, E., Andronopoulos, S., Bartzis, J., Vasilakos, C., 2010. PAHs sources contribution to the air quality of an office environment: experimental results and receptor model (PMF) application. Air Quality, Atmosphere \& Health 3, 225-234.

Seinfeld, J.H., Pandis, S.N., 2006. Atmospheric Chemistry and Physics - From Air Pollution to Climate Change, second ed. John Wiley \& Sons.

Valavanidis, A., Fiotakis, K., Vlachogianni, T., 2008. Airborne particulate matter and human health: toxicological assessment and importance of size and composition of particles for oxidative damage and carcinogenic mechanisms. Journal of Environmental Science and Health, Part C 26, 339-362.

Vecchi, R., Marcazzan, G., Valli, G., Ceriani, M., Antoniazzi, C., 2004. The role of atmospheric dispersion in the seasonal variation of PM1 and PM2.5 concentration and composition in the urban area of Milan (Italy). Atmospheric Environment 38, 4437-4446.

Wensing, M., Schripp, T., Uhde, E., Salthammer, T., 2008. Ultra-fine particles release from hardcopy devices: sources, real-room measurements and efficiency of filter accessories. Science of the Total Environment 407, 418-427.

Weschler, C.J., Nazaroff, W.W., 2008. Semivolatile organic compounds in indoor environments. Atmospheric Environment 42, 9018-9040.

Wilson, N.K., Chuang, J.C., Lyu, C., 2001. Levels of persistent organic pollutants in several child day care centers. Journal of Exposure Analysis and Environmental Epidemiology 11, 449-458. 